\title{
Educadores Sociais: 0 reconhecimento cotidiano e a organização de trabalho
}

\author{
Maria Luisa Magalhães Nogueira' \\ Cássia Beatriz Batista" \\ Alessandra Aguiar Vieira' \\ Cláudia Damasceno Pimentel ${ }^{\prime \prime \prime}$ \\ (Fapemig), Belo Horizonte/MG - Brasil
}

'Universidade Federal de Minas Gerais (UFMG), Belo Horizonte/MG - Brasil "Universidade Federal de São João del Rei (UFSJ), São João del Rei/MG - Brasil

"'Fundação de Amparo à Pesquisa do Estado de Minas Gerais

RESUMO - Educadores Sociais: o reconhecimento cotidiano e a organização de trabalho. Os programas sociais têm recrutado jovens moradores das periferias sociais, que passam a atuar profissionalmente por meio de políticas culturais, são os chamados educadores sociais. Partindo de uma pesquisa que interrogou as configurações do trabalho nesse contexto específico, apresentamos nesse texto as categorias reconhecimento e mobilidade psicossocial, bem como uma discussão histórico-política sobre educação social. A pesquisa utilizou histórias de vida, observação participante em uma oficina e duas entrevistas com educadores do Programa Fica Vivo! em Minas Gerais, analisadas por meio de categorização em análise cruzada. Percebemos que os processos de segregação que permeiam a relação cidade e alteridade estão presentes nesse cenário.

Palavras-chave: Psicologia do Trabalho. Cultura. Espaço. Educadores Sociais. Programas Sociais.

ABSTRACT - Social Educators: everyday recognition and work organization. Social programs have been recruiting young residents of social outskirts, who begin to act professionally through cultural policies - these are the social educators. Based on a research that questioned work configurations in this particular context, this text introduces categories such as recognition and psychosocial mobility, as well as a historical-political discussion on social education. The research used life stories, participant observation and two interviews with educators of the Fica Vivo! Program in Minas Gerais. The categorization in cross-examination was used for the analysis. We realize that the segregation processes which permeate the relationship between city and otherness are present in this scenario. Keywords: Work Psychology. Culture. Space. Social Educators. Social Programs.

Educação \& Realidade, Porto Alegre, v. 41, n. 4, p. 1289-1312, out./dez. 2016.1289 http://dx.doi.org/10.1590/2175-623655295 


\section{Introdução}

Pela primeira vez na história da humanidade, a cidade é o espaço privilegiado de moradia e vida da maior parte da população. Este fato reforça a importância de entendermos melhor os processos que atravessam, necessariamente, a vida urbana. Neste cenário, um elemento de crucial importância é o trabalho, não apenas pela sua centralida$\mathrm{de}^{\mathrm{l}}$, mas também por reconhecermos a importância de avançarmos na compreensão dos processos de (re)produção social, buscando entender as transformações que a atividade sofre na medida em que o capitalismo avança e conquista mais espaço, muitas vezes incorporando estratégias de resistência e criando novas necessidades e mercadorias. Deste modo, as teorias sociais vêm tentando articular melhor trabalho e espaço urbano.

Henri Lefebvre vem recebendo cada vez maior destaque por sua contribuição às análises do cenário social moderno. $\mathrm{O}$ autor, admirador da obra de Marx, foi capaz de colocar ênfase dos processos de domínio do espaço, que, para ele, é central na produção do poder no cotidiano, pois trabalha a urbanização como metáfora resumida da espacialização da modernidade, bem como do planejamento estratégico da vida cotidiana, elementos que possibilitaram a sobrevivência do Capitalismo. Para ele, a transformação do Capitalismo produziu uma revolução urbana ${ }^{2}$ justamente porque o sucesso de sua reprodução se apoiou num desenvolvimento geograficamente desigual, por meio de processos paralelos de homogeneização, fragmentação e hierarquização. Nesse cenário, o espaço, é tornado nova raridade e passa a ser um elemento de crucial importância nos modos do capitalismo resolver suas contradições:

O capitalismo descobriu-se capaz de atenuar (se não resolver) suas contradições internas durante um século e, consequentemente, nos cem anos decorridos desde a redação do Capital, logrou alcançar um crescimento. Não podemos calcular a que preço, mas realmente sabemos por qual meio: ocupando um espaço, produzindo um espaço (Lefebvre, 2008, p. 13).

Seja do ponto de vista global, seja na escala específica das cidades latino-americanas, um centro importante - simbólico e material - da produção do espaço urbano é a favela, não apenas como lócus de mão de obra barata, mas também como ponto de contraste na valorização simbólica de parcelas do solo, que passam a configurar como cada vez mais valorizadas na medida em que se reatualiza o estigma desse contexto como lugar da violência e informalidade. Ela, ainda, é produto direto dos processos de especulação imobiliária e valorização do solo.

Não sem razão, a primeira favela brasileira, o Morro da Providência, no Rio de Janeiro, nasceu a partir de intervenções do poder públi-

1290 Educação \& Realidade, Porto Alegre, v. 41, n. 4, p. 1289-1312, out./dez. 2016. 
co, pois a reforma Pereira Passos destruiu os cortiços, então, lócus das classes perigosas, e fomentou a necessidade da ocupação provisória/ precária do morro. Originalmente, no caso de Belo Horizonte, é o próprio plano da cidade que busca expulsar as classes trabalhadoras de seu tecido que faz com que os operários, fundamentais à construção da nova capital, ocupem parcelas da cidade que vão configurando favelas que, por sua vez, vão sendo expulsas, sem políticas habitacionais alternativas, criando outras favelas um pouco mais distantes. Como se sabe, os processos de especulação imobiliária são tanto geradores de espaços vazios à espera de valorização quanto impeditivos, pela supervalorização, da permanência legal dos pobres nas localidades mais bem equipadas da cidade, de modo que as favelas também surgem ligadas à ocupação do solo abandonado ou pela necessidade de proximidade com as centralidades urbanas, sendo o acesso ao trabalho um elemento importante dessa centralidade.

A favela sempre funcionou como campo de oferta de mão de obra. Atualmente, uma categoria específica de trabalhadores vem emergindo nesse cenário e passa a figurar como destaque cada vez maior: são os educadores sociais/oficineiros ${ }^{3}$ - foco deste texto. Os programas sociais, de cunho preventivo ou de atenção emergencial, de caráter público ou privado, têm recrutado jovens talentosos moradores dessas periferias sociais, que passam a atuar profissionalmente por meio da cultura. Imersos no contexto social marcado pela estigmatização e pobreza, espera-se que tais profissionais além de saber efetuar um ofício, saibam também 'dialogar com os jovens', construindo um espaço de mediação, ora tênue, entre os objetivos da política social na qual se inserem e as demandas próprias dos espaços em que vivem. Nesse sentido, diante das exigências que o trabalho lhes impõe e de seus mecanismos de enfrentamento, são eles o foco deste artigo, uma vez que uma aproximação de sua atividade permite não só apreender o que os mobilizam, mas também uma leitura ampla dos processos psicossociais que atravessam a relação cidade/trabalho. Deste modo, apresentaremos uma rápida contextualização da pesquisa que fundamenta as reflexões aqui desenvolvidas sobre a Categoria educadores sociais, bem como uma breve apresentação do que seria educação social. Em seguida, pontuarmos os elementos mais relevantes e que colocam essa categoria de trabalhadores, em emergência, já atravessada pelas contradições características da sociedade urbana, a saber: condições de trabalho, reconhecimento e mobilidade psicossocial.

\section{Contextualização da Pesquisa}

A pesquisa que produziu a discussão que vamos apresentar nesse texto, intitulada Trabalho, arte e cultura: as funções política e psicológica do trabalho realizado através de ações educativas artístico-culturais em contextos de vulnerabilidade social, foi desenvolvida com apoio da FA- 
Educadores Sociais

PEMIG entre 2008 e 2010, no âmbito de iniciação científica. Ela nasce da percepção de uma proliferação de projetos que lançam mão da cultura como possível dispositivo de promoção e/ou controle social, fez-se urgente a reflexão aprofundada sobre essa realidade.

A equipe da pesquisa foi formada em seu núcleo principal por cinco pesquisadoras, mas houve a participação de outros 12 estudantes de Psicologia, que se inseriram na pesquisa por meio do estágio supervisionado Culturas urbanas do curso de Psicologia da UFMG. O projeto teve como objetivo compreender a atividade do educador social, um trabalhador que atua em contextos de pobreza, usando práticas culturais como recursos de formação, capacitação, prevenção ou ocupação, atuando em programas e projetos de cunho público ou privado, tais como Programa de Controle de Homicídios - Fica Vivo!, em Minas Gerais (2009), e o Criança Esperança. Para tanto, a pesquisa recortou a regional centro-sul da cidade de Belo Horizonte e lançou mão de diversos recursos metodológicos, entre 2008 e 2012, a saber: análise documental (materiais do Programa Fica Vivo!), 12 histórias de vida ao longo de dois anos, duas entrevistas e realização de observação participante em uma oficina do Programa Fica Vivo! no Aglomerado Santa Lúcia, ao longo de um ano. O método de História de vida foi eixo central do trabalho e foi a fase que tomou a maior parte do tempo de desenvolvimento do estudo, dada sua peculiaridade.

O método de História de vida, dentro da metodologia de abordagem biográfica, de cunho qualitativo, já é bem estabelecido no campo científico brasileiro (Bosi, 1987) e também no exterior (Arfuch, 2002; Coulon, 1995; Ferraroti, 1990) tendo suas origens remontadas à Escola de Chicago, nos anos 20, e posteriormente no contexto europeu, do qual, os trabalhos desenvolvidos pela Psicossociologia e Sociologia clínica (Gaulejac, 1996; Levy, 2001) nos servem de norte, bem como a perspectiva sócio-histórica, com a qual dialogamos. Uma característica marcante desse método é justamente sua dimensão ética, uma vez que tem buscado colocar pesquisadores e entrevistados numa relação de horizontalidade, favorecendo a emergência da elaboração do vivido, para o entrevistado, de modo que ele não é colocado como objeto de pesquisa. Além disso, cada participante tem sua história transcrita e a recebe impressa ao fim do processo.

A partir dos diversos recursos metodológicos usados, pudemos ouvir e acompanhar esses trabalhadores em seu cotidiano. Após a primeira fase do estudo (recolhimento das histórias e análise), foram escolhidos os sujeitos para realização da entrevista em profundidade: uma educadora e um educador (este já havia recebido uma integrante da pesquisa como participante de sua oficina), cada um estava integrado a um núcleo distinto do Fica Vivo!, na mesma regional, em Belo Horizonte. Trabalhamos, assim, na etapa de entrevista, com uma amostragem por conveniência. Esses trabalhadores, aqui ficticiamente denominados de Bia e Hugo, foram convidados a darem as entrevistas tanto por se 
mostrarem mais acessíveis e disponíveis à equipe de pesquisa, quanto por já se colocarem como porta-vozes dos educadores nos núcleos dos programas em que estão inseridos e na cidade de forma mais ampla, atuando em diversas frentes e partícipes de movimentos sociais culturais. Percebemos, ao final da pesquisa, um enviesamento nesse percurso metodológico. Se por um lado, as entrevistas foram feitas com educadores que se colocavam numa condição de porta-vozes do grupo, por isso, mais acessíveis e com maior elaboração crítica sobre os programas, por outro lado, teria sido interessante uma escuta sensível dirigida aos educadores que permanecem em posições mais invisibilizadas, o que nos teria ampliado o horizonte, favorecendo o entendimento de como o discurso e a prática do programa reverbera no cotidiano desses sujeitos. Esse apontamento serve de indicativo para pesquisas futuras, ainda necessárias, sobre o tema. Outro ponto importante a se destacar é a necessidade de escuta também de educadores sociais pertencentes a localidades mais geograficamente periféricas, uma vez que as favelas em que circulamos na pesquisa em tela são bem servidas de equipamentos sociais e culturais e apresentam facilidades evidentes em termos de mobilidade em virtude de sua localização nobre no mapa da capital mineira.

A história de vida, bem como a História Oral e a História oral de Vida (Barros et al., 2007b; Portelli, 2002), não toma como objeto a questão da amostragem. Ela parte do pressuposto de que a escuta das histórias dos vencidos é relevante, uma vez que essas são histórias carregadas de legitimidade. Inclusive, segundo José Meihy (1996), no caso da história oral no contexto brasileiro, ela se destaca justamente por ter que emergir em busca do tempo perdido, configurando-se como história dos excluídos ou silenciados.

Vemos que cada história única está marcada pelos processos sociais, por isso, não se faz necessário um extenso banco de dados, mas sim uma escuta sensível e crítica, capaz de perceber os pontos sociais na costura do tecido de uma história singular. Nas histórias dos educadores ouvidos, lemos a história da cidade, a história das favelas como partes da cidade, a história da ausência de direitos nas favelas, a história da emergência dos projetos sociais em suas contradições, em suas idas e vindas, bordando significados e pluralidades diversas num desenho único. Apesar de tudo isso, nos preocupamos com a representatividade das falas colhidas, ainda que isso já tenha sido defendido pelas teorias que sustentam as metodologias biográficas. Na perspectiva utilizada (Barros et al., 2007a; Barros; Silva, 2004), a assertiva de Meihy também procede. Salientamos ainda que não se trata de dar voz aos excluídos, porque eles têm voz e se fazem audíveis das formas mais diversas no tecido social, mas trata-se de dar ouvidos' àqueles que historicamente foram levados a ocuparem posições de desqualificação social. Buscamos observar, com nossa pesquisa, se o contexto laboral em questão favorece uma ruptura desses processos de exclusão/inclusão perversa e em que medida.

Educação \& Realidade, Porto Alegre, v. 41, n. 4, p. 1289-1312, out./dez. 2016. 
Educadores Sociais

Assim, elaboramos os roteiros para as entrevistas semidirigidas a partir da análise do material coletado no recolhimento das histórias de vida, cuja análise obedeceu a um procedimento que denominamos de método de Categorização em análise cruzada ${ }^{4}$. A partir das categorias levantadas, realizamos as entrevistas em profundidade com dois educadores sociais: Bia (nome fictício), então com 24 anos; e Hugo (nome fictício), com 35 anos; e restringimos nesse texto o acesso ao conteúdo dessas duas entrevistas.

Após a conclusão, o estudo foi apresentado em uma devolutiva para um equipamento cultural independente (isto é, não na sede dos programas) em uma das localidades envolvidas, com a presença dos educadores ouvidos nas entrevistas. A experiência da devolutiva coletiva funcionou também como um mecanismo interventivo, favorecendo, por meio do grupo, a ampliação dos recursos de elaboração das contradições percebidas nessa realidade de trabalho. No presente artigo não apresentaremos todos os pontos desenvolvidos na pesquisa: seguiremos um eixo que parte da atividade de trabalho desses educadores e busca identificar que elementos psicossociais estão aí presentes. Assim, além de lançarmos interrogações sobre a relação cidade/trabalho, buscamos alcançar o ponto de vista dos trabalhadores, fazendo um movimento pendular entre o micro e o macrossocial. Porém, a discussão mais específica sobre a atividade, na perspectiva da clínica da atividade (Clot, 2010), não será aqui desenvolvida.

Os objetivos da pesquisa indicavam uma investigação sobre os modos de produção subjetivos produzidos na atividade de trabalho e as funções política e psicológica do trabalho realizado através de ações educativas artístico-culturais, em favelas da regional centro-sul da cidade de Belo Horizonte, Aglomerado da Serra e Aglomerado Santa Lúcia.

Além de reconhecermos a importância do trabalho na vida subjetiva-objetiva de todos nós, partimos também de interrogações dirigidas à contemporaneidade, ou seja, como as relações de trabalho se configuram nesse contexto específico (educadores sociais, moradores de favela) e como os processos de segregação que permeiam a relação cidade e alteridade estão presentes nesse cenário.

\section{O Programa Fica Vivo!}

O Programa Fica Vivo! é foco desse estudo - uma vez que contempla a maior parte dos educadores ouvidos na primeira fase desta pesquisa (recolhimento de histórias de vida), além de Bia e Hugo, na segunda fase (observação participante, análise de documentos e entrevistas em profundidade) - e [o programa] é voltado para jovens entre 12 e 24 anos, tendo como objetivo principal a redução da criminalidade, em nível primário, nos locais com alto índice de homicídios (Souza, 2008). O Programa Fica Vivo! está vinculado à Secretaria de Segurança Pública 
de Minas Gerais e é uma resposta ao aumento crescente da violência, principalmente no espaço urbano a partir da década de 1990, fato tal que não deixa de ser associado à figura da juventude nos espaços das favelas brasileiras. Entrelaçando, assim, política social com segurança pública, segundo argumenta Leite (2009, p. 120), superintendente de prevenção à criminalidade, o Fica Vivo! busca

[...] através de ações de proteção social, principalmente através de oficinas de cultura, esporte e inclusão produtiva, como mecanismo de aproximação e inclusão. Este programa articula, por meio de uma metodologia de intervenção estratégica, os órgãos de defesa social e sistema de justiça, visando à repressão qualificada em suas áreas de atuação.

Percebemos, pois, nas bases do programa uma intervenção primária, que visa antes de tudo à prevenção à criminalidade, porém que não deixa de instituir um paradoxo fundamental: a inclusão produtiva $\mathrm{e}$ repressão qualificada, elementos tais que, apresentados lado a lado nas propostas dos programas, podem se apresentar como estranhos, inconciliáveis. Nesse ponto, mesmo não sendo nossa proposta uma profunda aproximação das bases do programa Fica Vivo!, não podemos deixar de antever que tais contradições demarcam a atividade dos educadores sociais/oficineiros, uma vez que eles vivenciam ambos os lados: são moradores da favela e trabalhadores do programa, fato tal que também não deixou de atravessar as questões de nossa pesquisa. Outro ponto de destaque é a nomenclatura que esse trabalhador recebe: oficineiro ou educador social? Esse dilema vem sendo negociado com os próprios trabalhadores, o que é muito interessante, ao longo da existência do programa, conforme discutiremos mais a frente.

Vemos um esforço importante desses programas e projetos na busca pelo reconhecimento dos saberes locais e na valorização do lugar, que não é em nada desprezível, já que:

\begin{abstract}
[...] podemos entender os lugares como demarcações físicas e simbólicas no espaço, cujos usos os qualificam e lhes atribuem sentidos de pertencimento, orientando ações sociais e sendo por estas delimitados reflexivamente. [...] Os lugares, no entanto, guardam, de fato, estreita relação com certos aspectos mais perenes da vida social, do passado comum e do inconsciente das pessoas, como lembrava Bachelard (Leite, 2004, p. 35).
\end{abstract}

Deste modo, compreender que não se pode desprezar o sentimento de pertencimento que o sujeito constrói na relação com o lugar e que isso atua subjetivamente indicará avanços rigorosos. No entanto, na medida em que o trabalhador em questão tem como objeto de trabalho o próprio lugar, quais as consequências? 
Educadores Sociais

\section{Precarização do Trabalho de Educador Social}

O tema da Educação Social não deixa de ser polêmico, provocando dissensos entre os pesquisadores, principalmente no que se relaciona à tentativa de delimitação do saber-fazer dos sujeitos imersos nesse contexto. Desse modo, o debate atual evidencia algumas questões como: Quem são esses sujeitos? Qual a delimitação e especificidade do seu fazer que possibilita diferenciá-lo dos demais trabalhadores? Qual a formação necessária ao Educador Social para que suas visões de mundo possam ser tensionadas à luz da teoria (Gohn, 2010)? A fim de compreender tais questões, faz-se necessário resgatar um pouco da história desses sujeitos, contextualizando os marcos de atuação dos mesmos; caminho tal que nos possibilita apreender os impasses, percalços que se fazem presente na atualidade, seja em questões jurídicas, como a regulamentação da profissão, ou até mesmo na forma com que eles se nomeiam, em sua identidade profissional.

É certo que a década de 1990, momento de abertura política, evidenciou a complexidade dos problemas sociais que afligiam a população brasileira, marcando a necessidade da existência de trabalhadores que pudessem atuar junto às classes excluídas, principalmente na assistência em instituições da infância e adolescência. A esse profissional, cuja função seria a introdução de práticas corretivas de comportamento aos menores tidos como perigosos, deu-se o nome de Trabalhador social $^{5}$. Fundamentou-se, assim, nos primeiros anos da década de 90, a ideia de uma infância e adolescência problemática, considerada aversiva, sendo, pois, necessário domá-la, corrigi-la. Assim, conforme ressalta Pereira (2013, p. 06), “[...] o papel do trabalhador social no âmbito dessas instituições era o de manter a ordem vigente a todo custo e isso explica a construção preconceituosa em torno desses profissionais ${ }^{6 ”}$.

Em contrapartida, somente no final da década de 1970 e 1980, com o início da abertura política, que nasce o Educador Social, atrelado à educação popular, "que se constituía no principal referencial da luta pelo direito e cidadania dos que foram colocados à margem da escola" (Souza et al., 2014, p. 80). Fazia-se necessário, pois, a presença de "educadores sociais emancipadores"7, comprometidos com a condição do oprimido, cuja profissionalidade também girasse

[...] em torno de saberes sobre o fazer e o pensar determinado pela reflexão da prática educativa, que o qualifica para uma atuação transformadora, desenvolvendo nele competências psicofísicas, como, por exemplo, a capacidade de análise e crítica da realidade dos atores sociais que ele atende, ou ainda a capacidade de autonomização permanente em relação a sua prática, aos atores, aos agentes públicos e privados que articulam políticas de proteção, aos colegas de profissão, dentre outros (Pereira, 2013, p. 08).

1296 Educação \& Realidade, Porto Alegre, v. 41, n. 4, p. 1289-1312, out./dez. 2016. 
Surge, assim, o Educador Social, trabalhador solitário, imerso em questões sociais complexas, sem formação específica, tendo que 'inventar e reinventar' seu fazer. Nomeiam-se e são nomeados de várias formas, como: oficineiros, professores comunitários, monitores, integralizadores; nomes tais que desvelam uma tentativa de delimitação de seu saber-fazer, demarcando um exercício de construção de sua identidade $^{8}$. Tal confusão nesse âmbito é corroborada com a ideia de que ainda não se dispõe de uma sistematização livresca de toda a práxis do educador social, mesmo diante do fato de que a Pedagogia Social, Ciência acadêmica, tem se apropriado do tema para estudo. Diante disso, "não há uma identidade fechada no Brasil para o Educador Social, este profissional está sendo a cada dia, por meio de sua existência, de sua intervenção nos processos educativos que se colocam diante dele" (Souza et al., 2014, p. 81, grifos nossos).

Diante de um fazer que se constitui pela prática, lança-se a discussão sobre qual formação o Educador Social deve dispor, assim como quem poderá exercer tal função. Parece haver um consenso entre vários autores de que há necessidade de uma formação específica desses atores sociais, que os permitem transitarem por aspectos políticos, culturais e pelas redes de atendimentos das cidades. Ele precisa, assim,

\begin{abstract}
[...] ser capacitado para trabalhar junto com os sujeitos da Educação Social para além da especificidade técnica que este educador pode ter, transitando e conhecendo os saberes pertinentes à promoção cultural do sujeito. Isto implica em extrapolar, por exemplo, técnicas de jogos e brincadeiras, capoeira, esportes em geral, artes (Souza et al., 2014, p. 84).
\end{abstract}

Nesse viés de análise, Gohn (2010) também ressalta as lacunas metodológicas que existem no âmbito da educação no campo social, marcando a necessidade de criação de métodos, mesmo que provisórios, uma vez que o dinamismo e a mudança são marcas imprescindíveis a esse campo. Diante da complexidade do campo de atuação, parece compreensível a dificuldade de se definir o Educador Social e sua especificidade no mundo do trabalho, o que tem sido destacado na própria dificuldade do consenso de categorias envolvidas que lutam pela regulamentação da profissão do Educador (PL 5346/2009 ${ }^{9}$, apresentada pelo deputado Chico Lopes). Em tal documento, o Educador Social é descrito como o profissional que tem como função "garantir a atenção, defesa e proteção a pessoas em situações de risco pessoal e social. Procuram assegurar seus direitos, abordando-as, sensibilizando-as, identificando suas necessidades e demandas e desenvolvendo atividades e tratamento" (Brasil, 2009).

Nesse ínterim, se a normatização da profissão parece garantir os direitos dos profissionais, no âmbito das questões trabalhistas, assim como em delimitações éticas, rompendo, de certa forma, com a precarização do trabalho, deixa também transparecer certo engessamento do 
Educadores Sociais

campo desse trabalho que parece contradizer a própria lógica que impera a Educação Social. Pereira (2013, p. 11), ao abordar o impacto sobre a profissionalização e formação dos Educadores Sociais acentua que

[...] temos a clareza de que, quando defendemos a legalização da profissão de educação social, estamos querendo a regulação pelo Estado capitalista das atividades de trabalho e das competências profissionalizantes, bem como das regras e condutas do(a) profissional educador(a) social.

Além do mais, quando se define a exclusividade de atuação do Educador Social trata-se de impedir que outros atores da comunidade emerjam em entidades sociais, movimentos sociais, dentre outros. Tais contradições mostram-se presentes, seja na definição de escolaridade mínima, na formação necessária ao educador e principalmente na delimitação de quais os profissionais devem enquadrar-se nessa categoria, fazendo com que o consenso imediato seja impossível. Isso porque a normatização de tal categoria parece irromper em uma perda inexorável, pela própria adequação à regulação capitalista que enrijece a profissão, exigindo-lhe normas que dificultam o potencial criativo dos sujeitos no exercício de transformação da realidade.

Hugo - É eu acho que pra você ter uma turma, pra você dizer uma palavra, pra você dizer uma verdade pra determinado jovem você tem que ter bagagem pra isso, você tem que ter formação, você tem que saber o que está sendo discutido a respeito do público que você tá trabalhando; não é simplesmente o cara que ele é bom marceneiro, ele é bom educador. Ele pode ser cheio de preconceito, ele pode ser cheio de estigmas, de afirmações que mantém determinados preconceitos que pode ser prejudicial ao programa, entendeu?

Diante do exposto, como atrelar a liberdade de atuação, protagonismo do educador social, com as condições de direito associadas ao mundo do trabalho, afinal, há também a necessidade de combater-se uma precarização que é real e abarca a vida de muitos educadores sociais. Nesse ponto, o impasse se apresenta, o que torna a regulamentação da profissão do Educador Social conflituosa, apontando para um caminho ainda longo de discussões e embates. Resta ao Educador Social, nesse percurso, a busca pelo trabalho criativo, diante de tantas realidades que exigem uma forma diversa de atuação para que um vínculo com os jovens possa se concretizar, fundamentando as bases para uma possível mudança social.

Há limitações da dimensão evidentemente positiva da inserção nessa atividade, dadas especialmente pelo contexto institucional, isto é, pela estrutura do programa e a organização de trabalho tal como proposta, assim como pelo seu direcionamento ideológico, pois os educadores sociais, no contexto pesquisado, não possuem direitos trabalhistas, assistência médica e condições de trabalho adequadas, além de terem uma remuneração relativamente baixa considerando que são 
eles a base do programa, bem como recebem investimentos tímidos no que se refere à capacitação.

Hugo - É, quando você escreve o projeto, você tem que trabalhar 5 horas diárias, é 20 horas semanais diretamente com os jovens, você tem que oferecer uma disponibilidade de tempo pra encontrar teti a teti com os técnicos, pra conversar com os técnicos sobre o processo da sua oficina e uma vez por mês uma reunião coletiva com todos os educadores. Teoricamente funcionaria assim, né? Você recebe um valor e uma porcentagem você tem que guardar pra comprar material e pro lanche. É isso. [...] E tipo, eu tenho que programar aula, eu tenho que escrever relatório, esse tipo de ação não conta como tempo de aula. Então eu fui percebendo que eu trabalho muito mais do que o valor que eu recebo.

A imagem de reconhecimento está esboçada nos textos e projetos do programa, o que implica em determinadas condições de trabalho e, mesmo, na impossibilidade do alcance de alguns dos objetivos desses programas como, por exemplo, a própria questão da 'inserção' ou 'promoção social' do próprio jovem contratado. No entanto, o que se passa, muitas vezes, é a reatualização do estigma que caracteriza a relação que se estabelece com a favela desde seu surgimento, bem como a manutenção dessa população nessa camada social e econômica, por meio da precarização das condições de trabalho.

Hugo - É... mas quando você vê, quando você se insere no processo eu percebo lacunas que a impressão que eu tenho é que eles não fazem muita questão de suprir, sabe? Por exemplo, nós não somos é... nós somos educadores, porque a gente tem contratos que vencem. A gente não tem vínculo empregatício. Nós não temos vínculo nenhum com a Secretaria de Defesa Social e nem com a instituição que transita o recurso. Se a gente sofre um acidente durante o trabalho não é problema deles, é problema nosso, entendeu? [...] que ficou grávida e ela ficou...ela tem direito a cinco meses, esses cinco meses o Fica Vivo! não deu pra ela os direitos. Ela ficou sem receber os cinco meses que era direito dela por lei, lei trabalhista [...] Mas a gente não tem autonomia... por exemplo, a gente não tem recurso! Num primeiro momento você até acredita que você vai conseguir executar um projeto de montagem de um espetáculo com $\mathrm{R} \$ 800,00$ por mês. Mais aí cê vê que você precisa de recurso pro cenário, não tem! Você tem que tirar do seu salário. O professor de percussão precisa comprar instrumento de percussão - tem que tirar do salário dele, entendeu? Tem que tirar do mesmo recurso. Então começa a limitar e acaba que você começa a pagar pra trabalhar, entende?

O próprio programa não prima pela cidadania no tratamento do educador. Por vezes, segundo a percepção dos educadores, o que parece orientar a prática do programa é o mesmo preconceito que atravessa a história da favela no Brasil. Já que é um programa direcionado ao pobre, ao favelado, então não demanda um investimento adequado, ou seja, que qualquer coisa serve e que direitos historicamente adquiridos no contexto das lutas trabalhistas são ignorados por mecanismos vários que, ainda que não sejam ilegais, são injustos e indignos. 
Educadores Sociais

A precarização das condições de trabalho é evidente e a organização do trabalho mostra-se desfavorável ao educador, como indicam as entrevistas e as histórias de vida, a partir de vários indicadores: na ausência de carteira assinada; inexistência de benefícios; investimento tímido da formação continuada dos profissionais; remuneração insuficiente; responsabilização do educador por todo o funcionamento da oficina; falta de investimento na manutenção/promoção dos espaços utilizados. Além dessas condições, o processo de trabalho do educador social envolve uma tensão cotidiana entre o saber técnico versus saber investido dos educadores e indica uma tensão, em diversos momentos, relacionada ao controle da atividade, evidenciado tanto pela presença do agente de campo (profissional que visita mensal ou semanalmente as oficinas), quanto nos relatórios e demais informações constantes que os educadores têm que prestar.

Hugo - Moramos no lugar. A gente trabalha o dia inteiro e à noite a gente vai em casa, final de semana a gente passa em casa. Que a gente tem relação muito grande com a casa e com o entorno, entendeu? É isso que as pessoas precisam entender.

Bia - A relação com o jovem são, dentro da comunidade, são relações boas, assim, boas e também negativas também vai do olhar meu, o olhar meu para o jovem [...] tá no tráfico e aí as vezes você que mora ali há muito tempo, o menino entrou para o tráfico agora e ele acha que pode te comandar, ele acha que pode mandar em você, [...]. Eu participo da cultura e ele lá no tráfico e isso não interfere, não sei se é melhor ou pior não, cada um decidiu o que quis. E eu fico chateada, eu acho é triste nesse ponto que eu vejo que tem muito menino com capacidade em muitas coisas e que você tenta...

No que tange a questão do controle, há ainda o lugar simbólico contraditório que o educador se situa, como morador da localidade e 'informante' dos mecanismos policias de vigilância e disciplinamento, tanto que o Programa pertence à Secretaria de Segurança Social e coloca em relação cultura e polícia.

Outro aspecto relevante é a questão da constante extensão da jornada de trabalho, já que moram e trabalham no mesmo contexto geográfico e simbólico. Nesse aspecto, ficou evidente os limites delicados entre vigilância, controle e promoção social presentes no cotidiano, uma tensão que extrapola os limites do trabalho, mas que se apresenta na rotina laboral. Esses são elementos que podem indicar que o reconhecimento citado não se transmuta em ações direcionadas ao bem estar e a saúde dos trabalhares, na relação de poder com a esfera institucional. Assim, os trabalhadores estão objetalizados, isto é, há uma relação instrumental da instituição com esses trabalhadores.

Hugo - A cabeça de quem tá na gestão mesmo de secretário, dos subsecretários, dos coordenadores, dos programas, elas também tem que mudar, entendeu? Não adianta inserir um projeto teórico porque é muito bonito se você ler o projeto Fica Vivo!, o programa Fica Vivo! é um pro-

1300 Educação \& Realidade, Porto Alegre, v. 41, n. 4, p. 1289-1312, out./dez. 2016. 
Nogueira; Batista; Vieira; Pimentel

grama muito bonito, mas na prática é outra coisa. O Gepar é a polícia comunitária, aquela polícia que transita, que conhece todo mundo, que vai ser amigo e não sei o quê. A relação do Gepar com as oficinas e com os oficineiros, ela é delicada em muitas comunidades, sabe? Porque até então o Gepar ele é uma das outras ações que tão vinculada ao programa Fica Vivo! pra diminuir, né?... Pra reduzir a criminalidade, pra diminuir a criminalidade. É mais em algumas comunidades tem polícia que entra dentro da oficina, coloca todo mundo na parede inclusive o educador! Entende? E aí quando o educador vai falar: eu sou educador do FV - foda-se você é favelado! Entendeu? Então tem que ser uma mudança de comportamento de pensamento geral. Geral.

Entendemos, por fim, que a atividade de educador social funciona de modo potente na vida dos sujeitos que a desenvolvem especialmente porque ela oferece condições de criar e resistir. Ou seja, é uma atividade que possibilita que esses sujeitos possam reconhecer antagonismos e produzir estratégias transgressoras (de saúde e de enfrentamento) frente às dificuldades cotidianas. Essas dificuldades são inerentes ao olhar invisibilizante que a cidade lança sobre as favelas e seus moradores. Um ponto importante a se considerar, no entanto, é que, como indicam as entrevistas, as estratégias de resistência parecem encontrar dificuldades de extrapolar o âmbito individual, além de não estarem presentes no posicionamento de todos os educadores. Neste sentido, talvez falte justamente uma ampliação do espaço de troca entre os educadores, pois na esfera coletiva a resistência pode ganhar força e se materializar de modo mais satisfatório. Talvez essa desarticulação interesse ao programa, pois acaba por docilizar os trabalhadores, fazendo com que não questionem a precarização de sua condição. Ainda assim, há uma identificação com o programa por parte dos educadores, pois, por um lado, valoriza seu saber, gera oportunidade de trabalho e acredita na possibilidade de mudança social por meio dessas ações educativas, ainda que sejam limitantes. A relação afetiva com o local de pertencimento e com os jovens da sua comunidade atravessa o vínculo do educador com o programa, atenuando críticas e ampliando esperanças, por vezes.

Bia - [...] eu percebo que tem várias pessoas na frente que gostam do programa, gostam de trabalhar dentro, tem outros que estão por interesses de grana e eu acho que não dá pra viver sem isso e aí, hoje, eu percebo que as coisas caminham da maneira que tem que caminhar. Lógico que na vida tudo tem uma questão de política, isso no meu trabalho faz parte, e eu sou uma das pessoas que não atuo muito assim, eu gosto, exemplo, se eu tô com um jovem ameaçado de morte e eu tenho que ir lá no fim do mundo pra solucionar isso e o trem tá aqui na minha frente, então é isso uma das coisas que me angustiam. Mas tem um desempenho bastante bacana, o programa, né. A questão de redução de homicídios é uma coisa que realmente é uma coisa complicada, é difícil trabalhar sobre essa questão, difícil trabalhar com o jovem nesse sentido, né, porque hoje ele tá aqui e amanhã ele tá lá morto, entendeu.

Saulo Geber (2010) ressalta que os educadores/oficineiros atribuem grande valor à socialização possibilitada por suas ações educa- 
Educadores Sociais

tivas junto aos jovens nas oficinas. E, por conhecerem os jovens para além da oficina, desempenham uma postura de mediadores entre o programa/política e o público-alvo destes, postura essa de resistência, de ator social, de elemento formador dessa identidade profissional específica. As condições precárias das ações dirigidas aos jovens nos programas públicos são também destacadas nesse estudo, e que comprometem tanto a ação socializadora com os jovens quanto à profissionalização dos educadores.

\section{A Atividade do Educador: o reconhecimento, mobilidade psicossocial e cultura}

Observamos que um elemento marcante do trabalho desenvolvido por esses trabalhadores é o reconhecimento. Esse caráter simbólico e organizativo da atividade aparece em todas as histórias de vida e foi marcante nas entrevistas. Os sujeitos relatam como a atividade favorece a construção de um significativo olhar positivo, sobretudo para si mesmos, desenvolvido a partir da produção constante de um saber construído na relação com o jovem, ou seja, na esfera da alteridade. Entendemos que esse processo não está restrito à esfera do que comumente é denominado como autoestima, mas sim que há um alcance significativo, que vai além da produção de uma posição narcísica, autocentrada e de resignação ou admiração de sua própria história e identidade. Esse olhar vai além de uma avaliação de si mesmo, alcançando uma reflexão crítica (em alguns casos, política) de sua condição de classe. Assim, pode-se identificar uma fratura no processo de estigmatização que estavam submersos, mas que, conforme veremos mais a frente, os próprios programas sociais podem acabar por reatualizar.

O reconhecimento vivido pelos educadores é gerado na relação afetiva com os jovens na comunidade, e que permite, através de seu trabalho, produzir saberes sobre si, os pares, os outros, a comunidade, o trabalho, as relações sociais, seus pertencimentos e espaços de mobilidade. Ainda que, de forma contraditória, o discurso de reconhecimento dos programas provoca tanto uma quebra do estigma e dos muros sociais quanto reafirma o lugar periférico que faço parte, de condições precárias de vida e de trabalho. E mais, morar e trabalhar na comunidade determina uma dedicação de tempo integral, em que os trabalhadores têm sua vida sugada pelos programas. Assim, temos um reconhecimento que não permite mudanças, pelo contrário, mantém as relações de poder e dominação já conhecidas.

Mas o que é reconhecimento? De acordo com Honneth (Faria; Machado; Brachat, 2012), o reconhecimento pelos demais membros de uma comunidade é instrumento fundamental para a autonomia e a autorrealização dos indivíduos, uma vez que é no reconhecimento social intersubjetivo que os indivíduos e os grupos formam suas identidades. A perspectiva do autor lança luz sobre a importância das relações in-

1302 Educação \& Realidade, Porto Alegre, v. 41, n. 4, p. 1289-1312, out./dez. 2016. 
tersubjetivas de reconhecimento para a compreensão da dinâmica das relações e conflitos sociais, sendo útil para entendermos como a atividade desses trabalhadores está carregada de contradições, na medida em que funciona como fonte potente de reconhecimento entre pares que, por sua vez, não encontra materialidade na estrutura dos programas e da sociedade ampliada, desencadeando uma luta constante na tentativa de restabelecer ou criar novas condições intersubjetivas de reconhecimento.

Bia - Me sinto tranquila e ao mesmo tempo não, porque tem alguns espaços que te trava, te deixa você pra baixo, como por exemplo o Palácio das Artes [Grande teatro da cidade]; te trava, te dá, você uma postura que, pô, todo mundo pode, será que é só o poderoso que pode? E eu já não gosto dessa questão de poder, poder é uma das coisas que me deixam meio angustiada. Mas eu acho que hoje eu percebo isso que eu tenho direitos e posso circular, não tô fazendo nada de errado.

Hugo - Eu acho que cidadania é acesso a bens culturais, a bens educacionais, a uma boa qualidade de vida, a referências de organização, acesso - antes de mais nada-acesso. Acesso a tudo pra que você possa inclusive escolher o que você vai fazer, que tem direito de decisão, né? Eu penso que todo mundo ouvir todos os estilos musicais na mesma proporção as pessoas saberiam definir aquele que ele gosta ao invés do que a mídia impõe, né? É se todo tivesse acesso a médicos de qualidade a gente saberia definir qual é aquele que tá tratando mal e cobraria melhor dele, entende? É educadores, professores bem preparados pra formar, contribuir com a formação da sua cidadania, né? Eu acho que cidadania é isso, é ter acesso, é qualidade de vida, é definições da ética humana. A cidadania perpassa várias questões, né? Uma coisa é a teoria o que se define como cidadania outra coisa é o que ela... na prática ela é muito ampla do meu ponto de vista, ela é muito ampla.

A busca de tornarmos objetos-sujeitos gera um descentramento de si e nos coloca em relação às expectativas dos outros sujeitos, concretos ou não, representantes sociais. Assim, a luta se torna social ao exceder escopos pessoais e alcançar um grupo de sujeitos. Contudo, esse movimento não é motivado por questões econômicas em sua origem, mas por necessidade de reconhecimento (de direito, de autoestima e de amor), na maior parte das vezes. Existe toda uma dimensão de direitos que ainda não foi atendida no contexto da educação social, como veremos. E, nesse aspecto, Honneth retrata a expressão negativa do desrespeito que nos auxilia na discussão sobre reconhecimento, destacando que valores e direitos podem modificar-se no tempo, assim como os modos de desrespeito. Seriam três expressões negativas do desrespeito: o abuso ou exclusão; a violação de direitos e a desvalorização de diferentes formas de autorrealização. E estes afetariam a autoconfiança e formação de vínculos; o autorrespeito e a autoestima. (Faria; Machado; Bracht, 2012)

Os dados nos apontaram três vértices da dimensão positiva ${ }^{10}$ da vivência do reconhecimento, na produção do reconhecimento desses

Educação \& Realidade, Porto Alegre, v. 41, n. 4, p. 1289-1312, out./dez. 2016.1303 
Educadores Sociais

trabalhadores: a) esse olhar dos próprios educadores para si mesmos e para os processos sócio-históricos que os atravessam, atuando na produção subjetiva que constitui espaços de mobilidade e ação; b)dos jovens (relação afetiva); c) dos pares, ou seja, dos outros moradores da favela e, ainda, de outros atores urbanos, na forma da ruptura das fronteiras sociais e na inserção em outros cenários, antes tidos como interditos, tais como espaços culturais consagrados da cidade.

Essa divisão é puramente didática, uma vez que tais processos se atravessam. Por exemplo, a inserção num espaço cultural da cidade (como assistir ou apresentar um espetáculo no Palácio das Artes ou Teatro Municipal) atua no terceiro ponto, gerando acesso, mas também reverbera nos alunos (jovens, como os educadores) que, por sua vez, reconhecem o educador como fomentador dessa inserção, o que, ainda, alimenta o primeiro ponto, favorecendo o olhar positivo para si mesmo, conforme podemos ver na fala das entrevistas.

Como se vê, esses três elementos somados conferem novas experiências afetivas a esses trabalhadores e desestabilizam - de forma positiva - a identidade, gerando o que denominamos como mobilidade psicossocial (Nogueira, 2004). A mobilidade psicossocial é compreendida e nomeada, pelos educadores sociais, como possibilidade de acesso, mostrando-se de fato como ponto fundamental, remetendo-nos à questão do trabalho como um dos eixos principais.

A noção de mobilidade psicossocial (Nogueira, 2004) atravessa os campos espacial, econômico, social e subjetivo. Como sabemos, o valor do homem, assim como o do capital, vai depender em larga medida de sua localização no espaço. Essa relação pode ser percebida na observação da mobilidade espacial - que flui, basicamente, em função do poder aquisitivo - e é explicitada pela segregação ambiental - também constituída pelo elemento econômico (na produção das novas raridades). $\mathrm{O}$ espaço é aqui compreendido, como sugere Lefebvre (2008), não como um mero receptáculo da vida humana, mas dela constituinte. Ele favorecerá a conexão material e simbólica que permeia as relações de alteridade que, por sua vez, configuram as experiências de subjetivação. Assim, a mobilidade psicossocial refere-se aos movimentos psicossociais experimentados pelos sujeitos por meio da dimensão social (vínculos interpessoais, de classe, desempenho de papéis sociais, cultura, estigmas, etc.), abarcando ainda o âmbito subjetivo necessariamente implícito na questão social (ou seja, as representações daí decorrentes, a construção da identidade, autoestima, autonomia, necessidade de reconhecimento, etc.) e lançada materialmente ao plano espacial, este agindo sobre a matriz dos modos de produção. A mobilidade psicossocial é entendida, desta forma, na interrelação do objetivo com o subjetivo (dos fatos concretos às representações e significados; da experiência de autoconstrução à necessidade de subsistência), ao longo da trajetória de vida do sujeito.

1304 Educação \& Realidade, Porto Alegre, v. 41, n. 4, p. 1289-1312, out./dez. 2016. 
O parâmetro de mobilidade psicossocial está presente na importância desse processo de reconhecimento - uma relação de transferência e contratransferência com o jovem - e suas contradições. Também se encontra nas histórias de vida e aparece condensada em diversos momentos na entrevista com Bia.

Bia - Aí você vira um certo, não vou dizer um certo espelho, mas você vira algo que as pessoas já, né, exemplo, que [...] aí te vê dançando, aí vou lá dançar também, é mais questão de vida assim; questão da galera gostar também, questão do que você também vem demonstrar o trabalho. [...] como um jovem da minha oficina assim, que hoje eu considero ele um espelho pra minha vida, sabe? Que é um jovem que viu o pai dele matar a mãe a machadada e tal, e depois o pai dele foi morto e hoje ele tem um objetivo na vida dele, ele tá formando, o objetivo da vida dele é tornar um advogado, já tá na cabeça e não tem como tirar; é um bom dançarino, dança muito e tal e é um dos meninos que chegou pra dançar comigo muito, muito tenso, muito calado, um menino que não tinha nada pra expressar, e hoje ele é um menino que te dá muita volta no mundo, te faz pergunta que você não sabe responder. [...] Eu acho também que você acaba criando, alguns criam um espelho em você, tem muitos assim, às vezes as pessoas se gabam em relação às coisas, mas eu não, fico muito feliz, mas fico muito triste, porque às vezes o espelho desse menino poderia ser o pai e a mãe dele, sabe. Que aí eu fico também satisfeita que eu posso dar um caminho bom, não sei se é bom ou se é ruim, sei que é algum caminho que te leva a algumas posturas positivas, acho que é um pouco isso.

A imagem do espelho é usada em vários sentidos, sublinhando sempre a importância da relação com o outro e a emergência do reconhecimento, potente na experiência da alteridade. Ao mesmo tempo em que a educadora reconhece que sua trajetória passa a servir como uma ampliação de referencial de opções de identificação na vida dos jovens da localidade, ela mesma se reconhece e se inspira na vida dos jovens, movimentando de forma inusitada as relações de poder, identificação e diferenciação dos processos subjetivos.

Assim, a questão do acesso é, de fato, fundamental: acesso material, espacial, como também, simbólico. É o contato (o acesso) com a realidade que provoca o engendramento de novas práticas e refere-se ao direito à cidade, à quebra do preconceito que conforma o que é uma favela.

[...] o direito à cidade (não à cidade arcaica, mas à vida urbana, à centralidade renovada, aos locais de encontro e de trocas, aos ritmos de vida e empregos do tempo que permitem o uso pleno e inteiro desses momentos e locais etc.). A proclamação e a realização da vida urbana como reino do uso (da troca e do encontro separados do valor de troca) exigem o domínio do econômico (do valor de troca, do mercado e da mercadoria) (Lefebvre, 2010, p. 139).

Assim, temos que lembrar que o impedimento a esse contato, ou sua amplitude, inclusive o acesso a um trabalho reconhecido, tem mui-

Educação \& Realidade, Porto Alegre, v. 41, n. 4, p. 1289-1312, out./dez. 2016.1305 
Educadores Sociais

to a ver com a esfera do poder público e da ação da sociedade como um todo.

Bia - A cidade é um local que você, como vou dizer, cidade é onde você vincula, você vai pra todos os espaços. E a cidade dentro de um aglomerado é onde você vive, onde você conhece, você pessoalmente ou não. Então cidade pra mim é essa questão mesmo, de vincular. [...]

Vemos a emergência ou o fortalecimento do sentimento de participação social e, ainda, de ruptura com estigmas e preconceitos que atravessam a realidade da favela.

Bia - Então dentro da oficina eu aprendo e ao mesmo tempo eu ensino, eu mais aprendo que ensino [...]. Mas eu fico feliz de saber que tem algumas coisas que, graças a deus, agora eu consegui resolver, consegui manter, sabe, consegui trabalhar, sabe. Se um dia eu ir embora, eu fico feliz pelas coisas que eu conquistei, pelas coisas que eu fiz, não com orgulho, ao me ver crescendo, mas eu aprendi muito com muitas coisas, aprendi a lidar com o outro, que é um ponto muito complicado, quer dizer, nem sei se aprendi. Sei que tô aprendendo. E é isso aí.

Trabalhar significa cultivar. É cultura sobre a qual Sônia Viegas discorre na Conferência Trabalho e Vida (Viegas, 1989). Se o trabalho está tomado por sua dimensão positiva, como momento de afirmação do homem, é construção do ser. Trabalho, nesta acepção, é labor e nos remete à ideia de cultivo: "a cultura é cultivada, é fruto de um processo de enriquecimento, de um processo de transformação” (Viegas, 1989, p. 02). Cria significações e possibilita que o homem coloque de si no mundo. A autora apropria-se do sentido do trabalho como vida, identifica o trabalho como atividade que cria mais que objetos, mas significações que se desdobram indefinidamente.

A inserção positivamente reconhecida nessa atividade laboral amplia a percepção de si, o que entendemos como superior à simples produção de autoestima: trata-se da produção do devir, oferecendo outras possibilidades identitárias, novas óticas sociais e condições de sonho e produção de imaginário sobre si mesmo e sobre a cidade.

Bia - Pra mim o maior desafio foi saber essa questão de, acho que nem é saber, essa postura que posso me vincular, essa postura que eu posso entrar no Palácio das Artes. Porque algumas coisas me feriam, por exemplo, eu tenho vergonha, então isso me atrapalha também. Mas aí quando eu começo a trabalhar com jovem que me faz eu tentar, começo a ter algumas posturas também - como assim, né? Exemplo: será que o que a gente dança tem que ficar só aqui? Não. A gente dança, é, não tá atrapalhando ninguém, a gente tá fazendo uma arte que quer enfrentar o que tá ai; cada um vai transmitir o que quiser na dança. Então eu acho que é importante conhecer.

A cultura entra como elemento de crucial importância, pois confere um caráter disruptivo às trajetórias sociais geracionais, de modo que se, por um lado, esses sujeitos reconhecem nas trajetórias de seus

1306 Educação \& Realidade, Porto Alegre, v. 41, n. 4, p. 1289-1312, out./dez. 2016. 
pais e mães a importância do trabalho e seu valor simbólico agregado, por outro, percebem que conseguiram ir além, inserindo-se em camadas simbólicas outras, isto é, inegavelmente reconhecidas e meritórias, rompendo a reprodução social perversa.

Percebemos, então, que o educador apresenta uma função específica no lugar, favorecendo um deslocamento identitário, sendo reconhecido tanto pelos jovens que participam do programa quanto pela favela como um todo. Essa dimensão é fundamental, sobretudo por integrar o caráter organizativo e significante do trabalho. Nesse ponto, de forma genérica, é possível indicar que os educadores passam a estruturar o ciclo cotidiano pelas e nas tarefas da atividade, alterando (qualquer que seja) o modo de vida anterior. O trabalho organiza a rotina, limita e amplia os deslocamentos na localidade e na cidade como um todo, produz significados na forma de novos saberes e na elaboração das percepções de mundo. Assim, ele atua na inserção social (local e na escala da cidade); rotina e tempo -, quanto no que diz respeito à produção de subjetividade, por meio da criação presente na atividade. A experiência de autonomia (ainda que relativa, já que mediada e vigiada pelo programa) na esfera da criação e invenção confere a essa atividade forte importância na constituição desses atores como sujeitos ${ }^{11}$.

Bia - O programa vê o oficineiro como uma das pedras preciosas do programa; isso que eles falam pra gente, né. Vê como uma coisa muito forte assim; se não tem oficineiro, não tem jovem, pro jovem ter um programa, então, não dá.

Hugo - Um ano, dois anos, um processo árduo mesmo de lapidação, de você oferecer limites pras pessoas, de você fazer as pessoas ficarem felizes, eu acho que vale muito a pena, sabe? Eu todo dia assim... Hoje por exemplo tem aula, né? Num primeiro momento me dá uma preguiça! Mais porque eu tenho tanta coisa pra fazer e que eu preciso me desdobrar, mas quando elas chegam com aquela carinha, aquelas coisas, aí começa a gritar uma com a outra, aí eu fico ouvindo e aí você vai controlando, vai conversando, vai construindo junto, sabe? Sei lá, é uma sensação mesmo de que eu tô vivo e de que vale a pena o tempo todo de dedicação.

$\mathrm{O}$ trabalho, que não se restringe à sua esfera técnica-cognitiva, é um intervalo ineliminável da relação objetividade/subjetividade, de forma que os modos de subjetivação nele se afirmam de maneira ativa (nesse ponto reconhecemos a dimensão política do trabalho) em possibilidades de implicação, na busca de autonomia e de reconhecimento, nas estratégias de transgressão, resistência, defesa e transformação onde a dimensão inventiva, positiva, fundante, do trabalho permanece.

Dessa maneira, os educadores vivenciam, via contexto laboral, condições para elaborar resistências diante de uma realidade que naturaliza as favelas como os lugares da violência e perigo, ainda que isso não se apresente para todos os sujeitos ouvidos. No entanto, cabe perguntar em que medida essa realidade laboral já nasce como precarização da mão de obra juvenil-cultural. 
Educadores Sociais

\section{Considerações}

A efetivação do reconhecimento requer melhores condições de trabalho para os educadores/oficineiros com melhoria salarial; formação para os educadores/oficineiros; investimento nos espaços de realização das oficinas.

Ainda assim, é preciso se perguntar se é possível prevenir de fato a criminalidade como propõe o programa. Não podemos eleger a cultura, a educação ou trabalho e assim, os projetos socioeducativos e programas sociais como os salvadores do crime e únicos geradores de cidadania. O papel da cultura e do trabalho na contemporaneidade criam possibilidades de promoção de cidadania, mas o trabalho dominado, a educação reprodutora e cultura mantenedora não respondem à demanda de justiça e igualdade de direitos e acessos. Aliás, cultura e trabalho não são suficientes na prevenção à criminalidade, como colocado por este e outros programas sociais. De todo modo, não só ampliar a percepção do fenômeno da violência como um fenômeno social urbano, mas também rever o olhar e a abordagem adotados pelas políticas públicas dirigidas ao jovem morador de favela são essenciais para reinventarmos as formas de facilitar o acesso à cidade, aos direitos de todos.

Neste contexto, ainda que o trabalho educativo com oficinas de arte/cultura seja hoje uma referência comumente usada por projetos sociais, como possibilidade 'garantida' de acesso à inclusão e à cidadania, entendemos aí uma tendência que, sob um discurso de transformação, pode estar reiterando aquelas determinações sociais e alicerçando a construção de discursos vazios e ideologicamente sofisticados.

Recebido em 03 de maio de 2015 Aprovado em 24 de fevereiro de 2016

\section{Notas}

1 Ainda que haja autores que apresentem críticas a tal perspectiva (tais como André Gorz; Alain Touraine) e que a crítica para a atualização da teoria marxista seja sempre necessária, tal como propõe, por exemplo, Henri Lefebvre (2008), não é possível desconhecer a importância psicossocial e a permanência do estatuto de fundamento da vida social que é o trabalho.

2 O tecido urbano ocupa posição privilegiada na obra lefebvreana, já que a concentração da população acompanha a dos meios de produção. Para tanto, é preciso observar que sua concepção de urbano vai além do espaço construído, superando-o: o urbano é um conjunto de relações. Cabe esclarecer que a teoria lefebvreana é extensa e complexa e que não é apresentada em sua totalidade, de modo que fazemos referência ao autor para salientar a importância do chamado direito à cidade, bem como para contextualizar o cenário da pesquisa.

3 A nomeação de tais profissionais parece ser ainda algo em construção, não livre de polêmicas, conforme visto ao longo deste artigo. Em nossa pesquisa, optamos pelo termo educadores sociais por ter sido esse o vocábulo privilegiado nas falas dos sujeitos ouvidos no nosso trabalho de campo.

1308 Educação \& Realidade, Porto Alegre, v. 41, n. 4, p. 1289-1312, out./dez. 2016. 
4 Cada integrante da equipe de pesquisa (seis membros) faz sua leitura e categorização de três das histórias recolhidas; em seguida, cruzamos e confrontamos as categorias elencadas. Aquelas categorias que se repetiram entre as análises dos membros e que se apresentarem nas três histórias de vida analisadas, foram identificadas como pontos centrais para aprofundamento e alimentaram a produção do roteiro de entrevista semidirigida.

5 Porém, hoje existe um exercício de separação conceitual entre o Trabalhador Social e o Educador Social, sendo o primeiro ligado à assistência social e o último especificamente envolto pela intervenção socioeducativa (Machado, 2002).

6 Tal visão do trabalhador social, muitas vezes, ainda impera sobre o educador social, marcando, muitas vezes, um exercício de ruptura da mesma, ou seja, por meio de nomeações outras que impeçam qualquer associação com a prática corretiva, educacional das populações consideradas perigosas. Isso pode ser percebido no caso específico de nosso objeto de estudo: educadores sociais no Programa Fica Vivo!. No exercício de nomear sua atividade, tais sujeitos optam por oficineiros. Segundo Souza (2008, p. 04), pedagoga do programa, "O termo educador social traria um direcionamento pelo trabalho educativo no sentido de que os jovens estão excluídos socialmente e que o trabalho a ser feito seria educá-los para integrá-los na sociedade. Isto traria uma ideia de que os jovens são problemáticos e que nós sabemos o que é melhor para eles. O termo oficineiro nos pareceu mais apropriado, pois ele não traz em si um conceito estabelecido do fazer deste profissional. Daria mais liberdade para desenvolvimento de uma nova prática descolada do modelo escolar e nos ajudaria a aproximar dos jovens".

7 Cabe ressaltar que os primeiros educadores sociais foram marcados por sua atuação na rua (entre 1970 e 1993), sendo chamados de ESR (Educadores Sociais de Rua), cujos principais fundamentos teóricos-práticos foram as ideias de Paulo Freire (2014). Conforme aponta Oliveira (2004, p. 91), “[...] a partir daí, a intenção dos educadores de rua era ajudar as crianças de rua, mas com respostas que transcendessem a assistência social. A expectativa do educador era oferecer, além de seus serviços profissionais de pedagogo, compromisso pessoal, envolvimento político e investimento emocional".

8 Cabe destacar que o Educador Social já é reconhecido pela Classificação de Ocupações Brasileiras (CBO 5153-05), sendo descrito como os profissionais que visam a "garantir a atenção, defesa e proteção a pessoas em situações de risco pessoal e social. Procuram assegurar seus direitos, abordando-as, sensibilizando-as, identificando suas necessidades e demandas e desenvolvendo atividades e tratamento. "Nessa classificação, o Educador Social apresenta como sinônimos 'arte educador'; 'educador de rua'; 'educador social de rua'; 'instrutor educacional'; 'orientador socioeducativo'. Demonstra-se também uma tentativa de diferenciá-lo de ocupações relacionadas, como 'agente de ação social'; 'monitor de dependente químico'; 'conselheiro tutelar' e 'socioeducador"” (CBO, 2005).

9 "Reafirmamos e comprovamos a existência do campo da Educação Social como um trabalho específico orientado a garantir o exercício dos direitos dos sujeitos de nosso trabalho, e que nos exige permanente compromisso em seus níveis éticos, técnicos, científicos e políticos” (Brasil, 2009).

10 O termo 'positivo' aqui é usado não num sentido dicotômico ou valorativo (positivo Xnegativo), mas no sentido de que essas experiências são positivas por 
Educadores Sociais

adicionam recursos, somar experiências, ampliar repertórios de identificação, atuando na impulsão do desenvolvimento.

11 Para uma compreensão mais aprofundada sobre esse caráter organizativo do trabalho, seria interessante lançar mão dos recursos teóricos e metodológicos das clínicas da atividade (como a Clínica da atividade, tal proposta por Yves Clot (2010), bem como os recursos desenvolvidos no âmbito da ergonomia e da ergologia), que poderiam vir a favorecer a compreensão de como esse trabalho organiza e significa, bem como o tipo de inserção que ele permite, além de ampliar o entendimento sobre a forma de criação e desenvolvimento presente na atividade. Neste sentido, cabe ressalvar que percebemos nos educadores ouvidos nas entrevistas essa dimensão de criação (na dança e no teatro), mas sabemos que dança, teatro ou outras atividades artísticas também podem ser uma reprodução de gestos e movimentos, pois produção não é necessariamente criação ou invenção, podendo ser apenas reprodução.

\section{Referências}

ARFUCH, Leonor. El Espacio Biográfico. Dilemas de la subjetividad contemporánea. Buenos Aires: Fondo de Cultura Económica, 2002.

BARROS, Vanessa Andrade; GOMIDE, Adriana; NOGUEIRA, Maria Luísa. Território e Trabalho: condições e limites para as ações do sujeito social. In: MAYORGA, Claudia; PRADO, Marco Aurélio (Org.). Psicologia Social. Belo Horizonte: ed. Autêntica, 2007a. P. 239-254.

BARROS, Vanessa Andrade; SILVA, Aline; BARROS, Carolyne Reis; NOGUEIRA, Maria Luísa Magalhaes. "Conte-me sua história": reflexões sobre o método de história de vida. Mosaico estudos em Psicologia, Belo Horizonte, v. 1, n. 1, p. 25-35, out 2007b.

BARROS, Vanessa Andrade; SILVA, Lílian. A pesquisa em História de Vida. In: GOULART, Iris Barbosa (Org.). Psicologia Organizacional e do Trabalho. São Paulo: Casa do Psicólogo, 2004. P. 133-146.

BOSI, Ecléa. Memória e Sociedade: lembranças de velhos. São Paulo: EDUSP, 1987.

BRASIL. Câmara dos Deputados. PL 5346/2009. Dispõe sobre a criação da profissão de educador(a) social. Brasília, DF: 2009. Disponível em: <http://www2. camara.leg.br/proposicoesWeb/prop_mostrarintegra;jsessionid=A66B49B1F95 D26AEEB5F13948854361C.nodel?>. Acesso em: 08 fev. 2016.

CBO 5153-05. Educador Social. Brasília, Ministério do Trabalho e Emprego, 2015. Disponível em: <http://www.ocupacoes.com.br/cbo-mte/515305-educador-social>. Acesso em: 07 fev. 2016.

CLOT, Yves. Trabalho e Poder de Agir. Belo Horizonte: Fabrefactum, 2010.

COULON, Alan. A Escola de Chicago. Campinas: Papirus Editora, 1995.

FARIA, Bruno de Almeida; MACHADO, Thiago da Silva; BRACHT, Valter. A inovação e o desinvestimento pedagógico na Educação Física escolar: uma leitura a partir da teoria do reconhecimento social. Motriz: Revista de Educação Física, Rio Claro, Universidade Estadual Paulista, v. 18, n. 1, p. 120-129, 2012.

FERRAROTI, Franco. Histoire et Histoires de Vie. Paris: Méridiens Klincksieck, 1990. FREIRE, Paulo. Pedagogia do Oprimido. Rio de Janeiro: Editora Paz e Terra, 2014.

GAULEJAC, Vincent. Histoires de vie et choix théorique. Les Cahiers du Laboratoire de Changement Social, Paris, Université de Paris, v. 7, n. 1, jun. 1996.

1310 Educação \& Realidade, Porto Alegre, v. 41, n. 4, p. 1289-1312, out./dez. 2016. 
GEBER, Saulo Pfeffer. Jovens Educadores no Contexto de uma Ação Pública voltada para a Juventude na Periferia de Belo Horizonte. 2010. $147 \mathrm{f}$. Tese (Doutorado em Educação) - Programa de Pós-Graduação, Faculdade de Educação, Universidade Federal de Minas Gerais, Belo Horizonte, 2010.

GOHN, Maria da Glória. Educação Não Formal e o Educador Social. Atuação no desenvolvimento de projetos sociais. São Paulo: Cortez, 2010.

LEFEBVRE, Henri. Espaço e Política. Belo Horizonte: Ed. UFMG, 2008.

LEFEBVRE, Henri. O Direito à Cidade. São Paulo: Centauro, 2010.

LEITE, Fabiana. Sistema penal, segurança pública e prevenção à criminalidade. In: OLIVEIRA, Kris Brettas; OLIVEIRA, Gleiber Gomes (Org.). Olhares Sobre a Prevenção à Criminalidade. Belo Horizonte: Instituto Elo, 2009. P. 113-124.

LEITE, Rogério Proença. Contra-usos da Cidade: lugares e espaço público na experiência urbana contemporânea. Campinas: Ed. Da Unicamp, 2004.

LEVY, André. Ciências Clínicas e Organizações Sociais. Belo Horizonte: Editora Autêntica, 2001.

MACHADO, Evelcy Monteiro. Pedagogia e a Pedagogia Social: Educação não formal. In: MACHADO, Evelcy Monteiro; CORTELAZZO, Iolanda Bueno de Camargo (Org.). Pedagogia em Debate On Line - Textos. Curitiba: Universidade Tuiuti do Paraná, 2002. P. 97-104. V. 1. Disponível em: <http://www.boaaula.com.br/iolan$\mathrm{da} /$ producao/me/pubonline/evelcyl7art.html>. Acesso em: 10 fev. 2016.

MEIHY, José Carlos Sebe Bom. (Re)Introduzindo História Oral no Brasil. São Paulo: Ed. Xamã, 1996.

MINAS GERAIS. Programa de Controle de Homicídios - Fica Vivo!. Secretaria de Estado de Defesa Social. Superintendência de Prevenção à Criminalidade. Diretoria de Promoção Social da Juventude. Belo Horizonte, jun. 2009.

NOGUEIRA, Maria Luísa Magalhães. Mobilidade Psicossocial: a história de Nil na cidade vivida. 147f. 2004. Dissertação (Mestrado em Psicologia) - Faculdade de Filosofia e Ciências Humanas de Goiatuba (FAFICH), Universidade Federal de Minas Gerais, 2004.

OLIVEIRA, Walter Ferreira de. Educação Social de Rua: as bases políticas e pedagógicas para uma educação popular. Porto Alegre: Artmed, 2004.

PEREIRA, Antonio. A Regulamentação da Profissão de Educador Social e os Impactos Sobre a Profissionalização e Formação. Grupo de trabalho 20: Ocupações e profissões. In: CONGRESSO BRASILEIRO DE SOCIOLOGIA, 16, 2013, Salvador. Anais... Salvador: 2013. P. 1-21. Disponível em: <http://pt.scribd.com/ doc/279585807/REGULAMENTACAO-DA-PROFISSAO-DE-EDUCADOR-SOCIAL-Antonio-Pereira-Uneb\#scribd>. Acesso em: 10 fev. 2016.

PORTELLI, Alessandro. Apresentação. In: FREITAS, Sônia Maria de. História Oral: possibilidades e procedimentos. São Paulo: Humanitas, 2002. P. 9-14.

SOUZA, Ângela Nogueira. Oficineiros do Programa Fica Vivo: Que ofício é este? In: Encontro de Oficineiros do Programa Fica Vivo!, 1, 2008, Belo Horizonte. Anais... Belo Horizonte: 2008. P. 1-14.

SOUZA, Cléia Renata Teixeira; NATALI, Paula. Marçal; MULLER, Verônica Regina; PAIVA, Jacyara; BAULLI, Régis Alan. A atuação profissional e formação do Educador social no Brasil: uma roda de conversa. Interfaces Científicas - Educação, Aracaju, v. 3, n. 1, p. 77-88, out. 2014. Disponível em: <https://periodicos. set.edu.br/index.php/educacao/article/view/1633/982>. Acesso em: 10 fev. 2016. 
Maria Luisa Magalhães Nogueira é professora do Departamento de Psicologia da UFMG. Mestre em Psicologia Social/UFMG e Doutora em Geografia/UFMG.

E-mail: malu.mnogueira@gmail.com

Cássia Beatriz Batistaé professora do Departamento de Psicologia da UFSJ. Mestre em Psicologia Social/UFMG e Doutora em Psicologia/UFMG.

E-mail: cassiabeatrizb@gmail.com

Alessandra Aguiar Vieira é psicóloga da Pediatria do Hospital das clínicas/ UFMG. Mestre em estudos Psicanalíticos pela Ufmg. Foi bolsista de iniciação científica/FAPEMIG.

E-mail: ale.aguiarvieira@yahoo.com.br

Cláudia Damasceno Pimentel é psicóloga formada pela UFMG. Foi bolsista de iniciação científica.

E-mail: cla.pimentel@yahoo.com.br 